\title{
$\mathrm{R} C \& \mathrm{C}$
}

REVISTA DE CONTABILIDADE E CONTROLADORIA

\section{IMPACTO DAS FRAUDES CONTÁBEIS NO BANCO PANAMERICANO SOBRE A REPUTAÇÃO DA DELOITTE}

\section{IMPACT OF ACCOUNTING FRAUDS AT BANCO PANAMERICANO ON DELOITTE'S REPUTATION}

Recebido em 20.10.2013 | Aceite final em 17.04.2014 |

Nota: este artigo foi aceito pelo Editor Jorge Eduardo Scarpin e passou por uma avaliação double blind review

A reprodução dos artigos, total ou parcial, pode ser feita desde que citada a fonte.

PAULO FREDERICO HOMERO JUNIOR

Mestre em Controladoria e Contabilidade | Universidade de São Paulo | Professor substituto | Universidade Federal do Rio Grande do Sul | Faculdade de Ciências Econômicas | Avenida João Pessoa, 52 | Porto Alegre-RS | Brasil | CEP 90040-000 | Telefone (+5551) 3308.3487 | E-mail: paulo.junior@ufrgs.br |

\section{RESUMO}

A literatura aponta dois incentivos básicos para a qualidade dos serviços de auditoria: os riscos de litígio e os riscos de reputação associados à falta de qualidade nestes serviços. Este artigo tenta identificar se houve danos à reputação da Deloitte em decorrência do anúncio de fraudes contábeis no Banco Panamericano, avaliando as reações do mercado de capitais brasileiro a este evento. Para tanto, duas estratégias foram adotadas: estudo de eventos e teste de Chow. A amostra analisada foi composta pelas ações do índice Ibovespa em 09/11/2010, data do anúncio das fraudes no Banco Panamericano. Os testes estatísticos não deram suporte às hipóteses de que as ações de companhias auditadas pela Deloitte tiveram retornos anormais negativos nem retornos anormais menores do que as de companhias auditadas por outras firmas durante o período próximo a esta data, e tampouco à hipótese de que ocorreram rompimentos nas tendências dos retornos das ações de companhias auditadas pela Deloitte em maior proporção do que os ocorridos com ações de companhias auditadas por outras firmas. Estes resultados contrariam os verificados em contextos semelhantes em outros países, e parecem indicar que os auditores brasileiros não enfrentam riscos de reputação significativos. Dado que os riscos de litígio enfrentados por estes profissionais no país também são baixos. Os resultados apontam uma falta de incentivos à qualidade das auditorias no Brasil.

Palavras-chave: Auditoria. Risco de reputação. Estudo de eventos. Teste de Chow. 


\begin{abstract}
The literature points to two basic incentives for the quality of audit services: litigation risks and reputation risks associated to the lack of quality in such services. This article tries to investigate whether there were damages to Deloitte's reputation due to the announcement of accounting frauds at Banco Panamericano, evaluating the reactions of the Brazilian capital market to this event. For that, two strategies were adopted: event study and the Chow test. The sample analysed was composed by stocks of Ibovespa index at 11/09/2010, date of the announcement of accounting frauds at Banco Panamericano. The statistic tests did not support the hypotheses that the stocks of companies audited by Deloitte had negative abnormal returns nor abnormal returns lower than those of stocks of companies audited by other firms during the period near that date, and neither the hypothesis that there were breaks in stock returns tendency of companies audited by Deloitte in a greater proportion than there were with stocks of companies audited by other firms. These results are contradictory to some found in similar contexts in another countries, and seem to indicate that Brazilian auditors do not face significant reputation risks. Given that litigation risks faced by these professionals in the country are also low, the results point to a lack of incentives to audit quality in Brazil.
\end{abstract}

Keywords: Audit. Reputation risk. Event study. Chow test.

\title{
1. INTRODUÇÃO
}

A auditoria independente das demonstrações financeiras desempenha um importante papel no funcionamento dos mercados de capitais, visando prover maior confiabilidade às informações contábeis divulgadas pelas companhias abertas. No entanto, como é possível garantir a qualidade dos serviços prestados pelos auditores?

No Brasil, a Comissão de Valores Mobiliários (CVM) e o Banco Central do Brasil (BCB) estabeleceram o rodízio entre firmas de auditoria devido à falta de credibilidade que o mercado passou a apresentar em virtude da comprovação de falhas nos exames das demonstrações de instituições financeiras na década de 1980, visando preservar a independência dos auditores e diminuir os erros e fraudes relacionados ao processo de auditoria (OLIVEIRA; SANTOS, 2007). Após enfrentar resistências por parte da profissão e das companhias auditadas, a obrigatoriedade do rodízio foi revogada para as instituições sujeitas à regulação do BCB (IBRACON, 2011), mas ainda é exigida das demais companhias abertas sob fiscalização da CVM.

Análises sobre a efetividade do rodízio são contraditórias: enquanto Braunbeck (2010) conclui que a qualidade das auditorias é inferior quanto maior o tempo de relacionamento contínuo entre o auditor e a entidade auditada. Azevedo e Costa (2012) não encontram evidências de que o rodízio de firmas de auditoria reduza o gerenciamento de resultados nas empresas brasileiras.

Também, visando ampliar a qualidade dos serviços de auditoria, recentemente o Banco Mundial recomendou ao Brasil a criação de um órgão público com a finalidade específica de fiscalizar a atuação dos auditores independentes, nos moldes do estadunidense Public Company Accounting Oversight Board (PCAOB) (WORLD BANK, 2013).

Além das regulações estatais, a literatura internacional aponta dois tipos principais de incentivos econômicos aos esforços dos auditores para garantir a qualidade de seus trabalhos: os riscos de perdas em litígios decorrentes de danos causados a terceiros pela emissão de opiniões que induzam a 
decisões equivocadas (PALMROSE, 1988), e os riscos de perda de reputação, que podem comprometer a capacidade dos auditores em manter e ampliar sua clientela (CHANEY; PHILIPICH, 2002; SKINNER; SRINIVASAN, 2012; WEBER; WILLENBORG; ZHANG, 2008).

Porém, os riscos de perdas em litígios enfrentados pelos auditores no Brasil podem ser considerados baixos. As sanções impostas por órgãos fiscalizadores não são frequentes e tampouco costumam ter altos valores, e apenas recentemente se teve notícia de condenação judicial de grande monta a auditores, ainda passível de recurso (MENGARDO, 2013). Assim, o risco de reputação poderia assumir um papel preponderante como forma de incentivo à qualidade das auditorias realizadas no país.

Neste sentido, o anúncio de fraudes contábeis no Banco Panamericano, cuja repercussão pôs em cheque a qualidade dos serviços de auditoria prestados à instituição pela Deloitte, uma das quatro grandes firmas do setor, se mostra como uma boa oportunidade para investigar os riscos de reputação a que os auditores se encontram expostos no Brasil. Por isso, o objetivo desta pesquisa é identificar se houve impactos aos retornos das ações de companhias clientes da Deloitte no período próximo à data do anúncio destas fraudes, visando responder a seguinte questão: a divulgação de fraudes contábeis no Banco Panamericano afetou a reputação da Deloitte?

Os resultados obtidos, por serem inconsistentes com os observados em casos semelhantes ocorridos em outros mercados de capitais, apontam uma lacuna na literatura corrente a respeito dos riscos de reputação dos auditores, indicando a necessidade de considerar as características institucionais dos mercados onde eles atuam. Além disso, os resultados podem também subsidiar o debate sobre a necessidade de regulação da atividade de auditoria independente no Brasil.

0 artigo prossegue da seguinte maneira: na próxima seção, apresento o referencial teórico que embasou esta pesquisa. Na seção 3 descrevo o caso do Banco Panamericano, e na seção 4, os procedimentos metodológicos adotados. A seção 5 é dedicada à apresentação e discussão dos resultados obtidos, e a seção 6 , às considerações finais.

\section{REFERENCIAL TEÓRICO}

A literatura internacional indica que as firmas de auditoria têm dois principais incentivos para prover serviços de qualidade: quando evidenciados publicamente, serviços de baixa qualidade deixam-nas expostas ao risco de perder clientes (riscos de reputação) e sujeitas ao pagamento de multas e de indenizações a investidores que tenham sido prejudicados pela falta de qualidade destes serviços (riscos de litígio) (WEBER; WILLENBORG; ZHANG, 2008).

Schwartz (1997) argumenta que quando os auditores estão expostos ao risco de pagar indenizações a investidores calculadas com base no montante das perdas de recursos investidos, sem que haja uma definição legal clara das responsabilidades dos auditores, cria-se uma espécie de seguro em relação a investimentos de risco, que pode levar a um nível de esforço por parte dos auditores maior do que o necessário. Para a autora, o nível de esforço dos auditores seria otimizado em cenários nos quais eles fossem responsabilizados sempre que emitissem opinião equivocada, independentemente do zelo com que tivessem prestado seus serviços, e as sanções fossem estabelecidas sem relação com os montantes aplicados pelos investidores.

A descrição de Schwartz (1997) se aplica sobretudo ao contexto dos Estados Unidos, onde os riscos de litígio são elevados, não sendo raro encontrar condenações a auditores impondo-lhes multas na casa dos milhões de dólares. Já quanto aos riscos de reputação, há evidências observadas também em países onde os riscos de litígio não são tão elevados, como é o caso do Brasil, no qual não há tradição de conflitos diretos entre auditores e investidores e a atuação dos órgãos fiscalizadores não é rigorosa.

O caso mais célebre de perda de reputação dos auditores decorreu da revelação de erros contábeis 
relativos ao reconhecimento de partes relacionadas na Enron, auditada por uma das então cinco grandes firmas de auditoria do planeta, a Arthur Andersen. Em outubro de 2001, a Enron era a sétima maior companhia dos Estados Unidos em volume de receitas. Após o anúncio dos erros contábeis, o valor de mercado da Enron erodiu, e em dezembro daquele ano ela entrou com um pedido de recuperação judicial. As repercussões deste caso levaram também ao virtual desaparecimento da Arthur Andersen, acusada de obstruir a Justiça ao destruir documentos relativos a sua atuação na Enron (CHANEY; PHILIPICH, 2002).

Chaney e Philipich (2002) encontraram evidências significativas de reações negativas do mercado de capitais estadunidense em relação aos clientes da Arthur Andersen, observaram uma perda da confiança dos investidores em relação à qualidade dos serviços prestados pela firma. Hecker, Krieg e Pfauth (2006) relatam evidências semelhantes em relação aos clientes alemães da Arthur Andersen; na Espanha, porém, as evidências analisadas por Barbera e Martinez (2006) não apresentaram impactos sobre os clientes da firma naquele país.

O Caso Enron não foi, contudo, o único a despertar o interesse da comunidade acadêmica. Weber, Willenborg e Zhang (2008) relatam o caso da ComROAD AG, companhia alemã que entre os meses de fevereiro e abril de 2002 identificou e comunicou ao mercado o fato de que seu principal cliente era uma companhia fictícia, a qual respondia por $97 \%$ de suas receitas no ano de 2000 . Neste ínterim a KPMG, que prestava serviços de auditoria à ComROAD, abdicou de prestar seus serviços à companhia e anunciou que refaria seus procedimentos de auditoria relativos a todos seus clientes listados no mesmo segmento de mercado da ComROAD, voltado para companhias de pequeno e médio porte. As evidências analisadas por Weber, Willenborg e Zhang (2008) demonstram que os clientes da KPMG tiveram retornos anormais negativos nos períodos próximos aos principais eventos relativos ao caso, além de a KPMG ter sofrido uma perda mais expressiva de clientes no ano em que tais eventos aconteceram.

Skinner e Srinivasan (2012), por sua vez, relatam o caso da Kanebo, companhia japonesa que revelou em 2004 a existência de fraudes contábeis no período de 1999 a 2003, cujos efeitos acumulados tiveram um impacto negativo de $¥ 200$ bilhões sobre seu patrimônio líquido. A ChuoAoyama, afiliada japonesa da PwC, foi dispensada pela Kanebo e acabou por vir a ter suas atividades suspensas por dois meses pela autoridade reguladora japonesa. Os autores constataram que um quarto dos clientes da ChuoAoyama abandonaram a firma, o que corrobora a alegada importância da reputação para os auditores.

A exemplo do que ocorre no mercado brasileiro, os mercados de capitais da Alemanha e do Japão, em que ocorreram respectivamente os casos da ComROAD AG e da Kanebo, apresentam baixos riscos de litígio aos auditores independentes, segundo os autores dos referidos estudos. Mas a despeito de tal característica, os efeitos observados sobre a reputação dos auditores destas empresas indicam que os mercados de capitais de ambos os países oferecem incentivos para a qualidade dos serviços de auditoria.

No entanto, o nível de maturidade institucional e de relevância econômica destes mercados para a economia de seus países difere substancialmente da situação brasileira, historicamente o mercado de capitais não tem cumprido um papel proeminente na alavancagem de recursos para investimentos de longo prazo e de alta intensidade de capital (BOVESPA, 2000). Ainda assim, será que o mercado brasileiro oferece riscos de reputação aos auditores que possam vir a compensar os baixos riscos de litígios, tal qual o alemão e o japonês? O caso do Banco Panamericano, descrito na seção 3, se mostra como uma boa oportunidade para analisar esta questão. 


\section{O CASO DO BANCO PANAMERICANO}

O Banco Panamericano é uma instituição financeira de médio porte, com foco de atuação nos mercados de financiamento de veículos, de crédito consignado e de crédito pessoal. Em 09 de novembro de 2010 a instituição divulgou ao público um fato relevante, dando conta de que seu principal acionista controlador à época, o Grupo Sílvio Santos, decidira aportar na instituição o valor de R\$ 2,5 bilhões, obtidos mediante operação financeira contratada com o Fundo Garantidor de Créditos (FGC), com o objetivo de suportar os ajustes decorrentes da constatação de inconsistências contábeis que não permitiam que as demonstrações financeiras refletissem a real situação patrimonial do banco.

Basicamente, o Banco Panamericano vendia suas carteiras de crédito a instituições financeiras de maior porte, reconhecendo a receita de tais vendas, porém não baixava de seu ativo o montante destas carteiras, o que inflava o valor de seu patrimônio líquido. Além disso, estas mesmas carteiras eram vendidas para novos compradores, amplificando os efeitos da fraude. Ao cruzar as informações de outros bancos sobre as carteiras adquiridas do Panamericano, a fiscalização do Banco Central constatou que as mesmas carteiras haviam sido vendidas para mais de um comprador. Assim, em virtude do ajuste de $\mathrm{R} \$ 2,5$ bilhões, o patrimônio líquido de $\mathrm{R} \$ 1,6$ bilhão do Panamericano se tornou um passivo a descoberto de R\$ 900 milhões (FOLHA DE S. PAULO, 2010a).

Nos dias seguintes à divulgação do aporte de capital no banco, o caso ganhou ampla repercussão na mídia. O fato de o apresentador e empresário Sílvio Santos, uma das figuras públicas mais conhecidas do país, ter oferecido seu patrimônio pessoal em garantia ao empréstimo tomado junto ao FGC, provavelmente contribuiu para que esta repercussão fosse amplificada, escapando aos tradicionais espaços do noticiário econômico e ganhando destaque em jornais, revistas e telejornais, por meio de manchetes como "Panamericano expõe Deloitte e agências de risco" (ZAMPIERI, 2010), "Por que a Deloitte erra tanto" (GRANDILONE, 2010), "Deloitte ignorou rombo no banco de Sílvio Santos" (FOLHA DE S. PAULO, 2010b), "'Indignada', Deloitte nega ter maquiado rombo no Panamericano" (G1, 2010), "'Vamos restaurar nossa reputação', diz Deloitte" (BRONZATTO, 2010), "O ano que a Deloitte queria esquecer" (COSTA, 2010), "'Estamos apanhando muito', diz o presidente da Deloitte" (CARVALHO, 2010).

De modo geral, passou-se a questionar a atuação da Deloitte na auditoria independente das demonstrações financeiras do Banco Panamericano, afinal não havia ainda três meses desde que ela emitira seu relatório de revisão das Informações Financeiras Trimestrais (IFT) do banco relativas a 30 de junho de 2010, afirmando não ter conhecimento de nenhuma modificação relevante que devesse ser feita nestas demonstrações. Mas, embora, este provavelmente tenha sido o caso de maior repercussão envolvendo a Deloitte no Brasil, ele não foi o primeiro. A firma também teve seu nome associado a problemas contábeis envolvendo a Parmalat, em 2003, a Bausch \& Lomb, em 2005, e a Aracruz, em 2008 (GRANDILONE, 2010), e a Brasil Telecom e o Carrefour, em 2010 (COSTA, 2010).

Em relação ao Caso Panamericano, investigações subsequentes revelaram que o total da fraude chegava a R\$ 4,3 bilhões. Apesar disso, a Polícia Federal não encontrou indícios de que os sócios da Deloitte envolvidos nos trabalhos do Banco Panamericano tivessem participado ou que soubessem destas fraudes, razão pela qual eles não foram indiciados ao final do inquérito policial que apurou o caso (FOLHA DE S. PAULO, 2011a). Contudo, informações obtidas pela imprensa apontam de que a firma poderá vir a ser punida pelo Banco Central por omissão ou falha técnica, com multa de $\mathrm{R} \$ 500$ mil e a inabilitação de um de seus sócios durante 8 anos (FOLHA DE S. PAULO, 2011a, 2011b). 


\section{PROCEDIMENTOS METODOLÓGICOS}

Em linha com o referencial teórico apresentado na seção 2, procurei analisar se os eventos descritos na seção 3 tiveram impactos sobre o mercado de capitais brasileiro. Mais especificamente, busco respostas para as seguintes hipóteses:

H1: As ações de companhias auditadas pela Deloitte tiveram retornos anormais negativos no período entre 05/11/2010 e 11/11/2010;

H2: As ações de companhias auditadas pela Deloitte tiveram retornos anormais menores do que as de companhias auditadas por outras firmas, no período entre 05/11/2010 e 11/11/2010;

H3: O anúncio das fraudes contábeis no Banco Panamericano causou rompimentos nas tendências dos retornos das ações de companhias auditadas pela Deloitte em maior proporção do que os rompimentos ocorridos nas tendências dos retornos das ações de companhias auditadas por outras firmas.

De acordo com a Hipótese de Mercado Eficiente (HME), os mercados se ajustam rapidamente a novas informações (FAMA et al., 1969). Associada à HME está a ideia de passeio aleatório: uma vez que todas as informações disponíveis já estejam refletidas nos preços das ações, a variação de preço em determinada data refletirá apenas as informações divulgadas nesta data, representando um evento independente em relação aos preços anteriores (MALKIEL, 2003).

Uma das maneiras de testar a HME é por meio de estudos de eventos, sobre os quais Mackinlay (1997) oferece uma detalhada descrição, e que consistem dos seguintes passos: determina-se um evento de interesse e o período no qual os retornos dos títulos envolvidos serão analisados (janela do evento); medem-se os retornos anormais $\left(A R_{i t}\right)$ destes títulos durante a janela do evento, que consistem nas diferenças entre os retornos reais $\left(R_{i t}\right)$ que os títulos obtiveram e os retornos esperados $\left(E\left(R_{i t}\right)\right)$ caso o evento analisado não tivesse ocorrido. Para medir os retornos esperados dos títulos são utilizados modelos teóricos, conforme o modelo apresentado na equação 1 , em que o retorno esperado dos títulos é função do retorno de mercado $\left(R_{m t}\right)$.

$$
E\left(R_{i t}\right)=\alpha_{t}+\beta_{t} R_{m t}+\varepsilon_{i t}
$$

Para que os retornos esperados possam ser calculados, é preciso determinar ainda uma janela de estimação, ou seja, o período em relação ao qual serão coletados os dados relativos aos títulos sob análise para que se estime o modelo descrito na equação 1 . Além disso, é comum haver um intervalo entre ambas as janelas, evitando que a estimativa dos retornos esperados contenha influências do evento analisado. A Figura 1 demonstra os intervalos utilizados para este estudo.

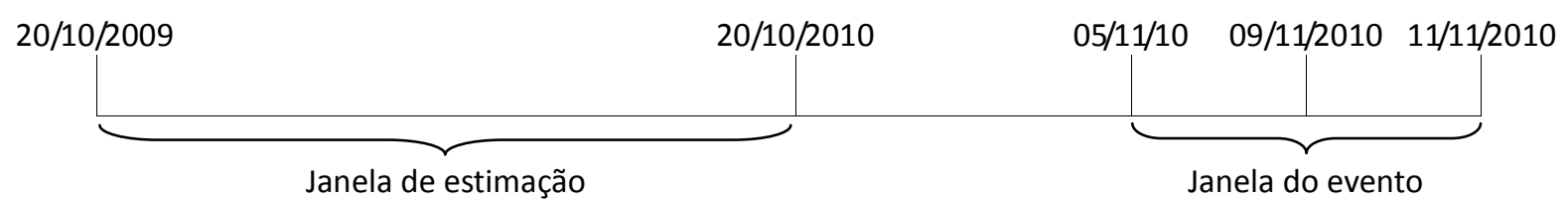

Figura 1: Intervalos do estudo de evento (fora de escala)

Dentro da janela do evento, os retornos anormais acumulados dos títulos entre os períodos 1 a $n$ $\left(\operatorname{CAR}_{\mathrm{i}}\left(t_{1}, t_{n}\right)\right)$ são calculados conforme descrito na fórmula 2, propiciando uma melhor análise dos efeitos do evento ao longo do período.

$$
\operatorname{CAR}_{i}\left(t_{1}, t_{n}\right)=\sum_{t=t_{1}}^{t_{n}} A R_{i t}
$$


Para este estudo, analisei os retornos anormais das ações que compunham o índice lbovespa em 09 de novembro 2010, data do anúncio das fraudes no Banco Panamericano. As ações que compõem o índice representam mais de $80 \%$ do número de negócios e do volume financeiro verificados no mercado à vista, e são responsáveis por aproximadamente $70 \%$ do somatório da capitalização de mercado de todas as empresas com ações negociáveis na BM\&FBOVESPA (BM\&FBOVESPA, 2013).

Calculei na forma logarítmica os retornos das ações e do próprio lbovespa, utilizado como retorno de mercado, com base nas cotações de fechamento ajustadas por proventos obtidas na base de dados da Economatica ${ }^{\circ}$. Desconsiderei os dias sem negociação na BM\&FBOVESPA, e para as ações que não foram negociadas em determinado pregão, adotei a última cotação de fechamento anteriormente disponível. Assim, a janela do evento, entre 05/11 e 11/11/2010, é composta por 5 pregões. Por fim, identifiquei os auditores independentes de cada uma das companhias à época consultando informações disponíveis no sítio eletrônico da CVM. Do total de 67 ações que compunham o índice Ibovespa em 09/11/2010, 16 eram de companhias auditadas pela Deloitte.

Calculados os retornos anormais de cada ação durante a janela do evento, apliquei testes $t$ para avaliar as hipóteses $\mathrm{H} 1$ e $\mathrm{H} 2$. Em relação à hipótese $\mathrm{H} 2$, utilizei também um teste não-paramétrico, $\mathrm{O}$ teste ordinal da soma de Wilcoxon, pois as distribuições dos retornos anormais em alguns intervalos dentro da janela do evento não atenderam simultaneamente aos critérios de normalidade das distribuições e igualdade das variâncias.

Já em relação à hipótese $H 3$, avaliei sua pertinência por meio do teste de Chow, cujo objetivo é identificar se houve, a partir de determinada data, mudança estrutural em um modelo de regressão, ou seja, se os parâmetros associados aos regressores se modificaram. A sistemática do teste consiste na estimação de três modelos: para o período anterior à data da suposta quebra de tendência, para o período posterior, e para o período completo. Na sequência, a soma dos quadrados dos resíduos das regressões relativas a cada sub-período é combinada e comparada à soma dos quadrados dos resíduos da regressão relativa ao período completo: se não houver mudança estrutural durante o período, então estes valores não deverão ser estatisticamente diferentes. A diferença estatística entre os modelos é testada por meio de um teste F (GUJARATI, 2006, pp. 222-223).

No caso sob análise, se o anúncio das fraudes contábeis no Banco Panamericano tiver alterado a percepção de risco dos investidores em relação às firmas auditadas pela Deloitte, então espera-se que a estrutura dos modelos que relacionam o retorno das ações destas firmas ao retorno de mercado tenham se rompido em proporção maior do que o das firmas que tenham outros auditores. O modelo de retorno aplicado foi o da equação 1 , e os intervalos analisados são representados na Figura 2.

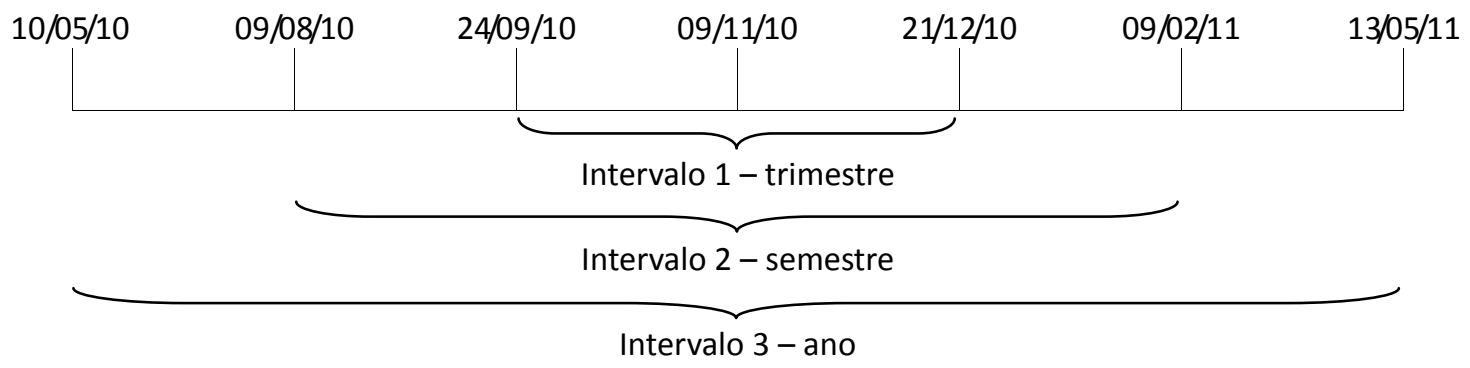

Figura 2: Intervalos dos testes de ruptura

Aplicando o teste de Chow para cada uma das companhias analisadas e em cada um dos três intervalos, utilizei o teste $z$ para comparar as proporções de títulos que tiveram suas séries alteradas a partir do anúncio das fraudes no Banco Panamericano, dentre aqueles de companhias auditadas pela Deloitte e os de companhias auditadas por outras firmas. 


\section{RESULTADOS}

A Tabela 1 contém as estatísticas descritivas dos retornos anormais acumulados em diversos intervalos dentro da janela do evento, segregados entre as companhias auditadas pela Deloitte e as auditadas por outras firmas, em que $t=0$ corresponde à data do evento.

Tabela 1: Estatísticas descritivas dos retornos anormais acumulados

\begin{tabular}{|c|c|c|c|c|c|c|c|c|c|c|c|c|}
\hline \multirow{2}{*}{$\begin{array}{c}\text { Intervalo } \\
\text { (t) }\end{array}$} & \multicolumn{2}{|c|}{ Média } & \multicolumn{2}{|c|}{ Mediana } & \multicolumn{2}{|c|}{ Mínimo } & \multicolumn{2}{|c|}{ Máximo } & \multicolumn{2}{|c|}{ Desvio Padrão } & \multicolumn{2}{|c|}{ C.V. } \\
\hline & Deloitte & Outras & Deloitte & Outras & Deloitte & Outras & Deloitte & Outras & Deloitte & Outras & Deloitte & Outras \\
\hline$(-2)$ & $-0,41 \%$ & $-0,03 \%$ & $0,17 \%$ & $0,04 \%$ & $-2,83 \%$ & $-2,91 \%$ & $1,49 \%$ & $5,40 \%$ & $1,40 \%$ & $1,46 \%$ & $343,82 \%$ & $5.012,10 \%$ \\
\hline$(-1)$ & $0,42 \%$ & $-0,30 \%$ & $0,60 \%$ & $-0,15 \%$ & $-3,69 \%$ & $-3,24 \%$ & $3,21 \%$ & $3,85 \%$ & $1,85 \%$ & $1,43 \%$ & $437,95 \%$ & $480,87 \%$ \\
\hline (0) & $0,27 \%$ & $0,27 \%$ & $1,27 \%$ & $0,43 \%$ & $-4,71 \%$ & $-4,57 \%$ & $2,32 \%$ & $3,94 \%$ & $1,89 \%$ & $1,92 \%$ & $707,15 \%$ & $702,70 \%$ \\
\hline (1) & $0,04 \%$ & $-0,06 \%$ & $0,03 \%$ & $0,20 \%$ & $-2,90 \%$ & $-3,35 \%$ & $2,56 \%$ & $3,07 \%$ & $1,56 \%$ & $1,48 \%$ & $4.040,20 \%$ & $2.503,90 \%$ \\
\hline$(2)$ & $-0,23 \%$ & $-0,08 \%$ & $-1,01 \%$ & $-0,27 \%$ & $-3,27 \%$ & $-3,93 \%$ & $7,25 \%$ & $4,09 \%$ & $2,36 \%$ & $1,76 \%$ & $1.047,60 \%$ & $2.240,40 \%$ \\
\hline$(-2,-1)$ & $0,02 \%$ & $-0,33 \%$ & $0,43 \%$ & $-0,82 \%$ & $-4,40 \%$ & $-4,41 \%$ & $2,38 \%$ & $4,21 \%$ & $1,86 \%$ & $1,80 \%$ & $11.642,00 \%$ & $552,63 \%$ \\
\hline$(-2,0)$ & $0,28 \%$ & $-0,05 \%$ & $1,02 \%$ & $-0,29 \%$ & $-5,31 \%$ & $-5,61 \%$ & $4,70 \%$ & $5,98 \%$ & $2,98 \%$ & $2,54 \%$ & $1.054,90 \%$ & $4.808,90 \%$ \\
\hline$(-2,1)$ & $0,32 \%$ & $-0,11 \%$ & $1,29 \%$ & $0,21 \%$ & $-8,22 \%$ & $-7,41 \%$ & $4,29 \%$ & $6,79 \%$ & $3,68 \%$ & $3,41 \%$ & $1.145,30 \%$ & $3.036,70 \%$ \\
\hline$(-2,2)$ & $0,10 \%$ & $-0,19 \%$ & $0,93 \%$ & $-0,33 \%$ & $-6,23 \%$ & $-8,62 \%$ & $3,54 \%$ & $9,07 \%$ & $3,33 \%$ & $3,52 \%$ & $3.468,90 \%$ & $1.843,30 \%$ \\
\hline$(-1,0)$ & $0,69 \%$ & $-0,02 \%$ & $1,15 \%$ & $0,75 \%$ & $-6,23 \%$ & $-7,26 \%$ & $4,45 \%$ & $4,09 \%$ & $2,99 \%$ & $2,54 \%$ & $433,70 \%$ & $10.676,00 \%$ \\
\hline$(-1,1)$ & $0,73 \%$ & $-0,08 \%$ & $0,69 \%$ & $0,35 \%$ & $-9,13 \%$ & $-8,47 \%$ & $7,00 \%$ & $6,11 \%$ & $4,06 \%$ & $3,31 \%$ & $558,64 \%$ & $3.982,10 \%$ \\
\hline$(-1,2)$ & $0,50 \%$ & $-0,16 \%$ & $0,68 \%$ & $0,08 \%$ & $-4,97 \%$ & $-6,85 \%$ & $6,05 \%$ & $7,67 \%$ & $3,39 \%$ & $3,07 \%$ & $675,27 \%$ & $1.896,80 \%$ \\
\hline$(0,1)$ & $0,31 \%$ & $0,21 \%$ & $0,38 \%$ & $0,45 \%$ & $-5,44 \%$ & $-6,27 \%$ & $3,82 \%$ & $6,23 \%$ & $2,65 \%$ & $2,74 \%$ & $868,81 \%$ & $1.283,50 \%$ \\
\hline$(0,2)$ & $0,08 \%$ & $0,13 \%$ & $0,60 \%$ & $0,05 \%$ & $-5,15 \%$ & $-6,21 \%$ & $3,34 \%$ & $8,23 \%$ & $2,52 \%$ & $2,66 \%$ & $3.144,60 \%$ & $1.973,70 \%$ \\
\hline$(1,2)$ & $-0,19 \%$ & $-0,14 \%$ & $-0,36 \%$ & $-0,22 \%$ & $-5,16 \%$ & $-5,16 \%$ & $4,34 \%$ & $5,57 \%$ & $2,24 \%$ & $2,06 \%$ & $1.202,70 \%$ & $1.496,10 \%$ \\
\hline
\end{tabular}

Fonte: Dados da pesquisa.

Uma análise preliminar das informações desta tabela já indica que dentre os 15 intervalos analisados, em apenas 3 as ações de companhias auditadas pela Deloitte tiveram retornos anormais médios negativos, o que contraria a hipótese $\mathrm{H} 1$, de que elas teriam retornos anormais negativos no período. Some-se a isso o fato de que somente em cinco intervalos as companhias auditadas por outras firmas tiveram retornos anormais médios maiores do que as ações de companhias auditadas pela Deloitte, rejeitando assim a hipótese $\mathrm{H} 2$.

Os testes de hipóteses apresentados na Tabela 2 corroboram esta visão. A um nível de significância de $10 \%$, não há suporte estatístico para a rejeição de nenhuma das três hipóteses nulas: de que a média dos retornos anormais acumulados das ações de companhias auditadas pela Deloitte seja maior do que zero, e de que a média e a mediana dos retornos das ações de companhias auditadas pela Deloitte sejam maiores do que as de companhias auditadas por outras firmas. Ou seja, os dados não dão suporte às hipóteses H1 e H2.

Tabela 2: Testes de hipóteses sobre os retornos anormais acumulados

\begin{tabular}{|c|c|c|c|c|c|c|}
\hline \multirow[t]{2}{*}{ Intervalo } & Mé & & Média ${ }_{\mathrm{De}}$ & dia outras & \multicolumn{2}{|c|}{$\begin{array}{c}\text { Mediana }_{\text {Deloitte }}>\text { Mediana }_{\text {Outras }} \\
\text { Somas de Wilcoxon } \\
(n 1=16, n 2=51)\end{array}$} \\
\hline & Estatística & Valor-p & Estatística & Valor-p & Estatística & Valor-p \\
\hline$(-2)$ & $-1,1634$ & 0,1314 & $-0,9105$ & 0,1830 & $-0,6029$ & 0,2733 \\
\hline$(-1)$ & 0,9133 & 0,8122 & 1,6348 & 0,9465 & 1,8382 & 0,9670 \\
\hline (0) & 0,5657 & 0,7100 & $-0,0112$ & 0,4955 & 0,1324 & 0,5526 \\
\hline (1) & 0,0990 & 0,5388 & 0,2274 & 0,5896 & 0,0000 & 0,5000 \\
\hline (2) & $-0,3818$ & 0,3540 & $-0,2667$ & 0,3953 & $-0,8824$ & 0,1888 \\
\hline$(-2,0)$ & 0,3792 & 0,6451 & 0,4415 & 0,6698 & 1,0147 & 0,8449 \\
\hline$(-1,0)$ & 0,9223 & 0,8145 & 0,9373 & 0,8240 & 0,6765 & 0,7506 \\
\hline$(0,1)$ & 0,4604 & 0,6741 & 0,1176 & 0,5466 & 0,6324 & 0,7364 \\
\hline$(0,2)$ & 0,1272 & 0,5498 & $-0,0728$ & 0,4711 & 0,7647 & 0,7778 \\
\hline$(-2,2)$ & 0,1153 & 0,5451 & 0,2881 & 0,6129 & 1,0147 & 0,8449 \\
\hline$(-1,1)$ & 0,7160 & 0,7575 & 0,8088 & 0,5784 & 0,5000 & 0,6915 \\
\hline$(-2,1)$ & 0,3492 & 0,6341 & 0,4358 & 0,6678 & 0,6471 & 0,7412 \\
\hline$(-1,2)$ & 0,5924 & 0,7188 & 0,7365 & 0,7680 & 0,0294 & 0,5117 \\
\hline$(-2,-1)$ & 0,0344 & 0,5135 & 0,6574 & 0,7434 & 0,2500 & 0,5987 \\
\hline$(1,2)$ & $-0,3326$ & 0,3720 & $-0,0806$ & 0,4680 & 0,1471 & 0,5585 \\
\hline
\end{tabular}

Fonte: Dados da pesquisa.

Revista de Contabilidade e Controladoria, ISSN 1984-6266

Universidade Federal do Paraná, Curitiba, v. 6, n.2, p. 40-53, maio/ago. 2014. 
Os intervalos destacados na Tabela 2 são aqueles que, de acordo com os testes descritos na Tabela 3, não atenderam aos critérios para a aplicação de testes paramétricos. Nestes casos, os resultados dos testes $t$ não devem ser levados em consideração.

Tabela 3: Testes de normalidade e de igualdade das variâncias dos retornos anormais acumulados

\begin{tabular}{|c|c|c|c|c|c|c|}
\hline \multirow{3}{*}{ Intervalo } & \multicolumn{4}{|c|}{ Normalidade (Jarque-Bera) } & \multirow{2}{*}{\multicolumn{2}{|c|}{ Igualdade das variâncias }} \\
\hline & \multicolumn{2}{|c|}{ Deloitte } & \multicolumn{2}{|c|}{ Outras } & & \\
\hline & Estatística & Valor-p & Estatística & Valor-p & $F(15 ; 50)$ & Valor-p \\
\hline$(-2)$ & 1,5510 & $0,4605^{*}$ & 17,7007 & 0,0001 & 1,0923 & $0,8939 *$ \\
\hline$(-1)$ & 0,6881 & $0,7089 *$ & 0,9523 & $0,6212^{*}$ & 1,6781 & 0,0867 \\
\hline (0) & 5,3095 & 0,0703 & 1,4993 & $0,4725^{*}$ & 1,0335 & $0,9975^{*}$ \\
\hline (1) & 0,3408 & $0,8433^{*}$ & 1,1030 & $0,5761^{*}$ & 1,1055 & $0,7520^{*}$ \\
\hline (2) & 24,0380 & 0,0000 & 0,7901 & $0,6737^{*}$ & 1,7908 & $0,1260^{*}$ \\
\hline$(-2,0)$ & 1,1331 & $0,5675^{*}$ & 0,2032 & $0,9034^{*}$ & 1,3783 & $0,3897^{*}$ \\
\hline$(-1,0)$ & 1,1393 & $0,5657^{*}$ & 9,8708 & 0,0072 & 1,1148 & $0,8564^{*}$ \\
\hline$(0,1)$ & 0,7121 & $0,7004^{*}$ & 0,7364 & $0,6920^{*}$ & 1,2209 & $0,5765^{*}$ \\
\hline$(0,2)$ & 1,0809 & $0,5825^{*}$ & 3,2011 & $0,2018^{*}$ & 1,0673 & $0,8173^{*}$ \\
\hline$(-2,2)$ & 1,7264 & $0,4218^{*}$ & 1,7950 & $0,4076^{*}$ & 1,1181 & $0,8510^{*}$ \\
\hline$(-1,1)$ & 0,7161 & $0,6990 *$ & 4,5938 & $0,1006^{*}$ & 1,5088 & $0,2763^{*}$ \\
\hline$(-2,-1)$ & 2,6112 & $0,2710^{*}$ & 0,4750 & $0,7886^{*}$ & 1,3720 & $0,3961^{*}$ \\
\hline$(-1,2)$ & 0,7383 & $0,6913^{*}$ & 1,2411 & $0,5377^{*}$ & 1,1669 & $0,6545^{*}$ \\
\hline$(-2,1)$ & 1,7893 & $0,4088^{*}$ & 1,5243 & $0,4667^{*}$ & 1,0685 & $0,9349^{*}$ \\
\hline$(1,2)$ & 0,3112 & $0,8559 *$ & 2,8116 & $0,2452^{*}$ & 1,1830 & $0,6305^{*}$ \\
\hline
\end{tabular}

*Significativo a $10 \%$.

Fonte: Dados da pesquisa.

Com relação à hipótese $\mathrm{H} 3$, a Tabela 4 apresenta os resultados dos testes de Chow, que também não oferecem suporte o fato que houve rompimentos nas tendências dos retornos das ações $d$ e companhias auditadas pela Deloitte em maior proporção do que os rompimentos ocorridos nas tendências dos retornos das ações de companhias auditadas por outras firmas, exceto quando analisado o intervalo 1 , relativo ao trimestre que tem a data do anúncio das fraudes no Banco Panamericano como ponto de ruptura. 
Tabela 4: Resultados dos testes de Chow

\begin{tabular}{|c|c|c|c|c|c|c|c|}
\hline \multirow{2}{*}{ Ação } & \multirow{2}{*}{ Auditor } & \multicolumn{2}{|c|}{ Intervalo 1 - Trimestre } & \multicolumn{2}{|c|}{ Intervalo 2 -Semestre } & \multicolumn{2}{|c|}{ Intervalo 3-Ano } \\
\hline & & $F(2,56)$ & Valor-p & $F(2,122)$ & Valor-p & $F(2,248)$ & Valor-p \\
\hline BBAS3 & Outro & 2,9882 & $0,0585^{*}$ & 1,7601 & 0,1764 & 0,5427 & 0,5819 \\
\hline ITUB4 & Outro & 1,9176 & 0,1565 & 1,2570 & 0,2882 & 0,2229 & 0,8004 \\
\hline BBDC4 & Outro & 2,0273 & 0,1412 & 1,9421 & 0,1478 & 0,5676 & 0,5676 \\
\hline PETR3 & Outro & 1,8894 & 0,1607 & 3,9276 & $0,0222^{* *}$ & 0,6030 & 0,5480 \\
\hline PETR4 & Outro & 1,3319 & 0,2722 & 4,2196 & $0,0169 * *$ & 0,5766 & 0,5625 \\
\hline SANB11 & Deloitte & 2,6635 & $0,0785^{*}$ & 3,5027 & $0,0332 * *$ & 1,4576 & 0,2348 \\
\hline ITSA4 & Outro & 1,5868 & 0,2136 & 1,9941 & 0,1406 & 0,9675 & 0,3815 \\
\hline VALE3 & Outro & 0,8303 & 0,4412 & 0,3318 & 0,7183 & 1,4449 & 0,2377 \\
\hline VALE5 & Outro & 0,7186 & 0,4919 & 1,0606 & 0,3494 & 5,3088 & $0,0055^{* * *}$ \\
\hline ELET3 & Outro & 2,2831 & 0,1114 & 1,7407 & 0,1797 & 0,2585 & 0,7724 \\
\hline ELET6 & Outro & 2,3559 & 0,1041 & 1,8955 & 0,1546 & 0,3690 & 0,6918 \\
\hline TMAR5 & Deloitte & 1,3340 & 0,2717 & 0,2735 & 0,7612 & 0,1229 & 0,8844 \\
\hline OIBR4 & Deloitte & 0,8373 & 0,4382 & 0,1420 & 0,8678 & 0,4199 & 0,6576 \\
\hline TNLP3 & Deloitte & 6,8580 & $0,0022 * * *$ & 1,2002 & 0,3047 & 0,5734 & 0,5643 \\
\hline TNLP4 & Deloitte & 3,0822 & $0,0537^{*}$ & 1,2860 & 0,2801 & 0,2705 & 0,7632 \\
\hline VIVT4 & Outro & 0,0731 & 0,9296 & 0,1851 & 0,8313 & 0,0976 & 0,9070 \\
\hline GOAU4 & Deloitte & 2,6282 & $0,0811^{*}$ & 4,3454 & $0,0150^{* *}$ & 0,9349 & 0,3940 \\
\hline GGBR4 & Deloitte & 3,1389 & $0,0510^{*}$ & 5,2575 & $0,0065^{* * *}$ & 1,2172 & 0,2978 \\
\hline AMBV4 & Outro & 0,4759 & 0,6238 & 1,9812 & 0,1423 & 0,2915 & 0,7474 \\
\hline CSNA3 & Outro & 3,0902 & $0,0533^{*}$ & 3,9540 & $0,0217^{* *}$ & 0,1464 & 0,8639 \\
\hline JBSS3 & Outro & 4,5591 & $0,0146^{* *}$ & 3,0197 & $0,0525^{*}$ & 0,6471 & 0,5245 \\
\hline BRKM5 & Outro & 1,9113 & 0,1574 & 0,0022 & 0,9978 & 0,5152 & 0,5980 \\
\hline CMIG4 & Outro & 0,2724 & 0,7625 & 0,5149 & 0,5989 & 1,0279 & 0,3593 \\
\hline PCAR4 & Outro & 0,4436 & 0,6440 & 1,0445 & 0,3550 & 0,7842 & 0,4576 \\
\hline USIM3 & Outro & 1,2915 & 0,2829 & 0,6473 & 0,5252 & 0,5337 & 0,5871 \\
\hline USIM5 & Outro & 1,2925 & 0,2826 & 2,0909 & 0,1280 & 0,9733 & 0,3793 \\
\hline BRFS3 & Outro & 1,1015 & 0,3395 & 0,7360 & 0,4811 & 0,4117 & 0,6630 \\
\hline CPFE3 & Outro & 0,2026 & 0,8172 & 0,0692 & 0,9332 & 0,2532 & 0,7765 \\
\hline FIBR3 & Outro & 2,4025 & $0,0998^{*}$ & 0,0740 & 0,9287 & 1,9595 & 0,1431 \\
\hline SBSP3 & Outro & 0,8791 & 0,4208 & 1,4456 & 0,2396 & 0,1984 & 0,8202 \\
\hline RDCD3 & Outro & 2,6292 & $0,0810^{*}$ & 0,9166 & 0,4026 & 2,9644 & $0,0534^{*}$ \\
\hline CSAN3 & Outro & 0,2887 & 0,7503 & 0,9517 & 0,3889 & 1,0751 & 0,3428 \\
\hline MRFG3 & Outro & 2,2407 & 0,1158 & 0,9338 & 0,3959 & 1,3954 & 0,2497 \\
\hline BVMF3 & Outro & 1,9072 & 0,1580 & 2,5694 & $0,0807^{*}$ & 2,1005 & 0,1246 \\
\hline TIMP3 & Outro & 3,0284 & $0,0564^{*}$ & 2,5122 & $0,0853^{*}$ & 0,4526 & 0,6365 \\
\hline TCSL4 & Outro & 0,1993 & 0,8199 & 0,2149 & 0,8069 & 0,2279 & 0,7964 \\
\hline VIVO4 & Outro & 0,1709 & 0,8433 & 0,5228 & 0,5942 & 1,2588 & 0,2858 \\
\hline CPLE6 & Deloitte & 0,4164 & 0,6614 & 0,2640 & 0,7684 & 0,8104 & 0,4459 \\
\hline EMBR3 & Outro & 0,4388 & 0,6470 & 0,5373 & 0,5857 & 0,5713 & 0,5656 \\
\hline PDGR3 & Outro & 0,0005 & 0,9995 & 0,6596 & 0,5189 & 0,1625 & 0,8501 \\
\hline OGXP3 & Outro & 1,2003 & 0,3087 & 1,6070 & 0,2047 & 1,9527 & 0,1441 \\
\hline CESP6 & Deloitte & 1,4007 & 0,2549 & 0,0327 & 0,9679 & 1,2829 & 0,2791 \\
\hline TAMM4 & Outro & 0,6202 & 0,5415 & 0,8284 & 0,4392 & 1,0640 & 0,3467 \\
\hline CCRO3 & Outro & 0,8026 & 0,4532 & 0,4356 & 0,6479 & 0,7784 & 0,4603 \\
\hline ALLL3 & Outro & 1,3053 & 0,2792 & 1,1999 & 0,3047 & 1,0089 & 0,3661 \\
\hline KLBN4 & Deloitte & 2,8088 & $0,0688^{*}$ & 1,5006 & 0,2271 & 1,9654 & 0,1423 \\
\hline UGPA4 & Outro & 0,6171 & 0,5432 & 1,9151 & 0,1517 & 0,8793 & 0,4164 \\
\hline CYRE3 & Outro & 1,3563 & 0,2659 & 3,0444 & $0,0513^{*}$ & 0,6003 & 0,5494 \\
\hline LIGT3 & Outro & 3,1632 & $0,0499 * *$ & 0,5569 & 0,5744 & 2,0492 & 0,1310 \\
\hline BRAP4 & Outro & 0,4224 & 0,6576 & 0,1555 & 0,8562 & 1,1926 & 0,3052 \\
\hline MRVE3 & Deloitte & 1,1028 & 0,3390 & 1,2601 & 0,2873 & 1,2450 & 0,2897 \\
\hline ELPL4 & Outro & 2,4595 & $0,0947^{*}$ & 1,9650 & 0,1446 & 1,3077 & 0,2723 \\
\hline BISA3 & Deloitte & 0,3556 & 0,7023 & 1,7511 & 0,1779 & 2,4200 & $0,0910^{*}$ \\
\hline LAME4 & Outro & 3,6136 & $0,0334^{* *}$ & 6,6793 & $0,0018^{* * *}$ & 2,4226 & $0,0908^{*}$ \\
\hline TRPL4 & Outro & 0,4675 & 0,6290 & 3,0820 & $0,0495^{* *}$ & 3,7009 & $0,0261^{* *}$ \\
\hline GOLL4 & Deloitte & 0,5211 & 0,5967 & 0,6779 & 0,5096 & 0,7466 & 0,4751 \\
\hline GFSA3 & Outro & 0,7588 & 0,4730 & 3,6857 & $0,0279 * *$ & 2,7764 & $0,0642^{*}$ \\
\hline CIEL3 & Deloitte & 1,2980 & 0,2812 & 0,8994 & 0,4095 & 1,7952 & 0,1682 \\
\hline RSID3 & Outro & 0,1697 & 0,8443 & 0,2000 & 0,8190 & 0,8802 & 0,4160 \\
\hline DTEX3 & Outro & 0,2207 & 0,8026 & 1,5721 & 0,2118 & 2,3421 & $0,0982 *$ \\
\hline$\overline{\mathrm{MMXM3}}$ & Outro & 0,6841 & 0,5087 & 0,7586 & 0,4705 & 0,4633 & 0,6297 \\
\hline CRUZ3 & Outro & 1,7188 & 0,1886 & 3,1588 & $0,0460 * *$ & 4,7029 & $0,0099 * * *$ \\
\hline NATU3 & Deloitte & 0,3608 & 0,6988 & 1,5328 & 0,2201 & 3,3041 & $0,0384 * *$ \\
\hline BTOW3 & Outro & 0,5180 & 0,5986 & 0,7806 & 0,4604 & 0,1987 & 0,8199 \\
\hline LREN3 & Outro & 1,4525 & 0,2427 & 5,3314 & $0,0060 * * *$ & 1,0419 & 0,3543 \\
\hline LLXL3 & Outro & 0,6558 & 0,5229 & 0,8213 & 0,4423 & 0,7547 & 0,4712 \\
\hline VAGR3 & Deloitte & 0,1752 & 0,8397 & 0,3981 & 0,6725 & 0,0561 & 0,9455 \\
\hline \multicolumn{8}{|c|}{ *** Significativo a $1 \%$} \\
\hline ** Significativ & & & & & & & \\
\hline * Significativo & & & & & & & \\
\hline Fonte: D & & & & & & & \\
\hline
\end{tabular}


Mas mesmo no intervalo 1 a proporção de ações de companhias auditadas pela Deloitte que sofreram ruptura na tendência de seus retornos fica abaixo de $50 \%$, como indica a Tabela 5 , o que contraria a hipótese de que os eventos ligados ao Banco Panamericano tenham causado danos severos à reputação da firma.

Tabela 5: Proporções das ações que sofreram ruptura na tendência dos retornos

\begin{tabular}{|c|c|c|c|c|c|c|c|c|c|c|c|c|c|}
\hline \multirow[b]{2}{*}{ AUDITOR } & \multirow[b]{2}{*}{ TOTAL } & \multicolumn{4}{|c|}{ INTERVALO 1 - TRIMESTRE } & \multicolumn{4}{|c|}{ INTERVALO 2 - SEMESTRE } & \multicolumn{4}{|c|}{ INTERVALO 3 - ANO } \\
\hline & & $\begin{array}{l}\text { Significativo } \\
\text { a 10\% }\end{array}$ & Proporção & $\begin{array}{l}P_{\text {Deloit }} \\
z\end{array}$ & 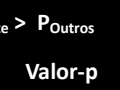 & $\begin{array}{l}\text { Significativo } \\
\text { a } 10 \%\end{array}$ & Proporção & $\begin{array}{c}P_{\text {Deloitte }}= \\
z\end{array}$ & $\begin{array}{l}\text { Poutros } \\
\text { Valor-p }\end{array}$ & $\begin{array}{c}\text { Significativo } \\
\text { a 10\% }\end{array}$ & Proporção & $\begin{array}{c}P_{\text {Deloitte }} \\
z\end{array}$ & $\begin{array}{l}\text { Poutros } \\
\text { Valor-p }\end{array}$ \\
\hline Deloitte & 16 & 6 & $37,50 \%$ & \multirow{2}{*}{1,6618} & \multirow{2}{*}{$0,04828 * *$} & 3 & $18,75 \%$ & \multirow{2}{*}{$-0,4002$} & \multirow{2}{*}{0,6555} & 2 & $12,50 \%$ & \multirow{2}{*}{$-0,1259$} & \multirow{2}{*}{0,5501} \\
\hline Outro & 51 & 9 & $17,65 \%$ & & & 12 & $23.53 \%$ & & & 7 & $13,73 \%$ & & \\
\hline
\end{tabular}

Fonte: Dados da pesquisa.

Diante destes resultados, nenhuma das hipóteses testadas se mostrou pertinente. Assim, o caso do Banco Panamericano parece indicar que os abalos na reputação de um auditor não impactam o mercado brasileiro de capitais.

\section{CONSIDERAÇÕES FINAIS}

Ao analisar possíveis efeitos da divulgação de fraudes contábeis no Banco Panamericano sobre o mercado brasileiro de capitais, procurei evidências de que o impacto deste caso sobre a reputação da Deloitte, firma que prestava serviços de auditoria ao banco, tivesse afetado os retornos das ações dos demais clientes da firma. Os resultados do estudo de evento e dos testes de ruptura aplicados não deram suporte às hipóteses que as ações de companhias auditadas pela Deloitte tiveram retornos anormais negativos ou menores que os das demais companhias no período próximo à data do anúncio do caso, e tampouco de que tenha havido rompimentos nas tendências dos retornos das ações de companhias auditadas pela Deloitte em maior proporção do que os rompimentos ocorridos nas tendências dos retornos das ações de companhias auditadas por outras firmas.

Tais resultados permitem uma ampla gama de interpretações. Em primeiro lugar, é preciso considerar a possibilidade de que a amostra selecionada não seja a mais adequada para este estudo. Optei por avaliar os retornos das ações que compunham o índice lbovespa à época da divulgação do caso pelo fato de elas terem um alto volume de transações, uma das condições necessárias para que seus preços possam refletir rapidamente os efeitos de novas informações. Contudo, a inclusão de um número maior de ações na amostra poderia conduzir a resultados distintos, além de permitir a análise de variáveis de controle relativas ao porte e ao setor de atuação de cada companhia, por exemplo.

Outra possibilidade é o fato de que o mercado de capitais brasileiro não seja eficiente em relação às informações sobre os auditores independentes. Assim, os danos à reputação dos auditores não seriam refletidos rapidamente nos preços das ações de seus clientes. Estudos a respeito do impacto do caso Panamericano diretamente sobre o mercado de auditoria, que avaliem alterações no valor dos honorários e no número de clientes da Deloitte após este evento, poderão vir a corroborar com esta pesquisa.

Mas o caso Panamericano não foi o único de problemas contábeis envolvendo a Deloitte no Brasil, conforme descrevi na seção 3. Então, é possível que a reputação da firma já estivesse deteriorada antes deste caso, e um eventual "Custo Deloitte" já estivesse refletido nos preços das ações de seus clientes. Estudos que incluam tais casos em seus escopos e que avaliem os reflexos da contração da Deloitte sobre os preços das ações de seus clientes, poderiam sustentar esta conjectura ou, por outro lado, evidenciar que nenhum destes casos de fato abalou a reputação da firma. 
A possibilidade que me parece mais preocupante é a de que as firmas de auditoria não incorram em riscos de reputação no Brasil. A aparente indiferença do mercado de capitais brasileiro aos danos causados à reputação da Deloitte pelo caso do Banco Panamericano, sugerida pelos resultados desta pesquisa, associada ao baixo risco de litígios que os auditores enfrentam no país, condiz a um cenário onde não existem os dois principais incentivos econômicos descritos na literatura para realização de trabalhos de auditoria com qualidade. E, mesmo que o caso Panamericano tenha afetado diretamente o mercado de auditoria, ainda assim estaríamos diante de uma situação longe da ideal, sugerindo que as preocupações dos auditores devessem se voltar a suas reputações perante seus clientes, e não junto ao público em geral, o que poderia incentivar práticas que comprometam a requerida independência destes profissionais.

Por fim, considerando as características do mercado de auditoria, marcado por um oligopólio global em que apenas 4 firmas atendem a praticamente todos os clientes de grande porte, e ainda o perfil cada vez mais globalizado dos diversos atores do mercado de capitais, inclusive dos investidores, talvez não faça sentido analisar em nível local o fenômeno da reputação dos auditores. É possível que apenas a marca de uma Big Four baste aos investidores, independentemente dos problemas que estas firmas venham a enfrentar em cada um dos diversos países onde atuam.

No entanto, esta ideia contraria os achados de Weber, Willenborg e Zhang (2008) sobre o mercado de capitais alemão, e até certo ponto também as de Skinner e Srinivasan (SKINNER; SRINIVASAN, 2012) sobre o mercado japonês de auditoria. Portanto, pode-se imaginar também que o mercado brasileiro tenha um nível de influência menor sobre a reputação dos auditores do que os mercados alemão e japonês, e futuros estudos deveriam levar explicitamente em consideração as características institucionais dos mercados de atuação destes profissionais.

\section{REFERÊNCIAS}

AZEVEDO, F. B.; COSTA, F. M. Efeito da troca da firma de auditoria no gerenciamento de resultados das companhias abertas brasileiras. Revista de Administração Mackenzie, v. 13, n. 5, p. 65-100, 2012.

BARBERA, C. D. F.; MARTINEZ, M. C. P. The stock market reaction to the Enron-Andersen affair in Spain. International Journal of Auditing, v. 10, n. 1, p. 67-85, Mar. 2006.

BM\&FBOVESPA. Índice Bovespa - Ibovespa. Disponível em: <http://www.bmfbovespa.com.br/ indices/Resumolndice.aspx?Indice=Ibovespa\&Idioma=pt-br>. Acesso em: 1 fev. 2013.

BOVESPA. Desafios e oportunidades para o mercado de capitais brasileiro. Jun. 2000. Disponível em: $<\mathrm{http}: / /$ www2.bmf.com.br/cimConteudo/W_Livros/mercado_capitais_desafios.pdf $>$. Acesso em: 12 abr. 2014.

BRAUNBECK, G. O. Determinantes da qualidade das auditorias independentes no Brasil. 2010. Tese (Doutorado em Controladoria e Contabilidade) - Faculdade de Economia, Administração e Contabilidade, Universidade de São Paulo, São Paulo, 2010.

BRONZATTO, T. "Vamos restaurar a nossa reputação", diz Deloitte. Exame, 18 nov. 2010. Disponível em: <http://exame.abril.com.br/noticia/vamos-restaurar-a-nossa-reputacao-diz-deloitte/imprimir>. Acesso em: 19 out. 2013.

CARVALHO, D. "Estamos apanhando muito", diz o presidente da Deloitte. Exame, 31 dez. 2010. Disponível em: <http://exame.abril.com.br/noticia/estamos-apanhando-muito/imprimir>. Acesso em: 19 out. 2010.

CHANEY, P. K.; PHILIPICH, K. L. Shredded reputation: the cost of audit failure. Journal of Accounting Research, v. 40, n. 4, p. 1221-1245, set. 2002.

COSTA, A. C. O ano que a Deloitte queria esquecer. Veja, 01 out. 2010. Disponível em: 
<http://veja.abril.com.br/noticia/economia/o-ano-que-a-deloitte-queria-esquecer>. Acesso em: 1 fev. 2013.

FAMA, E. F.; FISHER, L.; JENSEN, M. C.; ROLL, R. The adjustment of stock prices to new information. International Economic Review, v. 10, n. 1, p. 1-21, 1969.

FOLHA DE S. PAULO. Rombo no banco PanAmericano pode superar R\$2,5 bilhões. Folha de S. Paulo, 15 nov. 2010a. Disponível em: <http://www1.folha.uol.com.br/mercado/830717-rombo-no-bancopanamericano-pode-superar-r-25-bilhoes.shtml>. Acesso em: 1 fev. 2013.

FOLHA DE S. PAULO. Deloitte ignorou rombo no banco de Silvio Santos. Folha de S.Paulo, 17 nov. 201b0. Disponível em: <http://www1.folha.uol.com.br/mercado/831729-deloitte-ignorou-rombo-nobanco-de-silvio-santos.shtml>. Acesso em: 1 fev. 2013.

FOLHA DE S. PAULO. PF desiste de indiciar Deloitte em caso do PanAmericano. Folha de S.Paulo, 02 nov. 2011a. Disponível em: <http://www1.folha.uol.com.br/mercado/831729-deloitte-ignorourombo-no-banco-de-silvio-santos.shtml>. Acesso em: 1 fev. 2013.

FOLHA DE S. PAULO. Auditores do PanAmericano devem ser punidos pelo BC. Folha de S.Paulo, 24 nov. 2011b. Disponível em: <http://www1.folha.uol.com.br/mercado/1011114-auditores-dopanamericano-devem-ser-punidos-pelo-bc.shtml>. Acesso em: 1 fev. 2011.

G1. "Indignada", Deloitte nega ter maquiado rombo no Panamericano. G1- Economia e Negócios. 17 nov. 2010. Disponível em: <http://g1.globo.com/economia-e-negocios/noticia/2010/11/indignadadeloitte-nega-ter-maquiado-rombo-no-panamericano.html>. Acesso em: 19 out. 2013.

GRANDILONE, C. Por que a Deloitte erra tanto. Isto é Dinheiro, 12 nov. 2010. Disponível em: $<$ http://www.istoedinheiro.com.br/noticias/41059_POR+QUE+A+DELOITTE+ERRA+TANTO>. Acesso em: 3 fev. 2013.

GUJARATI, D. N. Econometria Básica. Rio de Janeiro: Elsevier, 2006.

HECKER, R.; KRIEG, A.; PFAUTH, A. The effect of auditor reputation on stock returns: the case of Arthur Andersen. 25 Oct. 2006. University of Tuebingen Disponível em: <http://dx.doi.org/10.2139/ ssrn.939276>. Acesso em: 19 out. 2013.

IBRACON. Não ao rodízio obrigatório de auditorias. Revista Transparência Ibracon, p. 27-31, 2011.

MACKINLAY, A. Event studies in economics and finance. Journal of economic literature, v. 35, n. 1, p. 13-39, 1997.

MALKIEL, B. The efficient market hypothesis and its critics. Journal of economic perspectives, v. 17, n. 1, p. 59-82, 2003.

MENGARDO, B. Price é condenada em R\$ 25 milhões. Valor Econômico, 29 ago. 2013. Disponível em: <http://www.valor.com.br/legislacao/3250944/price-e-condenada-em-r-25-milhoes>. Acesso em: 18 out. 2013.

OLIVEIRA, A.; SANTOS, N. Rodízio de Firmas de Auditoria: a experiência brasileira e as conclusões do mercado. Revista Contabilidade \& Finanças, v. 18, n. 45, p. 91-100, 2007.

PALMROSE, Z.-V. An analysis of auditor litigation and audit service quality. The Accounting Review, v. 63, n. 1, p. 55-73, 1988.

SCHWARTZ, R. Legal regimes, audit quality and investment. The Accounting Review, v. 72, n. 3, p. 385406, 1997.

SKINNER, D. D. J.; SRINIVASAN, S. Audit Quality and Auditor Reputation: Evidence from Japan. The Accounting Review, v. 87, n. 5, p. 1737-1765, set. 2012. 
WEBER, J.; WILLENBORG, M.; ZHANG, J. Does auditor reputation matter? The case of KPMG Germany and ComROAD AG. Journal of Accounting Research, v. 46, n. 4, p. 941-972, set. 2008.

WORLD BANK. Brazil: report on the observance of standards and codes (ROSC): accounting \& auditing. World Bank. 11 June 2013. Disponível em: <http://www.fgv.br/mailing/fgv_noticias/_pdfs/ Report-on-the-Observance-of-Standards-ROSC.pdf>. Acesso em: 17 mar. 2014.

ZAMPIERI, A. C. Panamericano expõe Deloitte e agências de risco. iG. 10 nov. 2010. Disponível em: <http://economia.ig.com.br/mercados/panamericano-expoe-deloitte-e-agencias-derisco/n1237824218016.html>. Acesso em: 19 out. 2013. 